$\$=$

\title{
Implementation of an educational programme for caregivers of the elderly in Windhoek and Rehoboth, Namibia
}

\author{
Joan M. Kloppers, Agnes van Dyk ${ }^{1 *}$, Lucia N. Nelumbu ${ }^{2}$ \\ ${ }^{1}$ University of Namibia University of Namibia University of Namibia \\ ${ }^{2}$ Private Bag 13301340 MandumeNdemufaye Ave, Pionierspark Windhoek \\ *Corresponding author E-mail: jkloppers@unam.na
}

\begin{abstract}
In many instances care for the frail elderly, especially in long-term care institutions, is provided under minimal supervision by caregivers who lay people. This can lead to poor-quality care or neglect of the frail elderly. Therefore, caregivers have a major role in coordinating comprehensive long-term care.

One of the objectives of the study "Caregiving in old-age homes in Windhoek: A practice-orientated enquiry into caregiving education" was to implement the educational programme for caregivers in old age homes in Windhoek. A qualitative, explorative, descriptive, contextual and phenomenology design was used to perform this study.

The study was conducted in three phases. Firstly, a situational analysis was carried out to explore and describe the experiences and needs of the caregivers and the elderly. The situation analysis revealed themes in terms of interpersonal relationships that could be positive or negative regarding the elderly, with the sub-themes like communication, support and caring for elderly people. These themes and subthemes include the following: Interpersonal relationships were viewed as an important aspect of the caring process. Lack of regular inservice training sessions for caregivers, with a sub- theme of a lack of adequate knowledge of procedures. Lack of human resources, equipment and policies

In the second phase, a conceptual framework was derived from the results of phase 1, using the activities prescribed by Dickoff, James and Wiedenbach (1968). In the third phase, a programme was developed from the findings of the previous phase. Finally, the educational programme was implemented and evaluated in old-age homes in Windhoek.
\end{abstract}

Keywords: Caring; Caregiver; Elderly; Old Age Home and Programme.

\section{Introduction}

This article was extracted from the authors study "Caregiving in old-age homes in Windhoek: A practice-orientated enquiry into care giving education." After the development of the educational programme it was implemented to determine the effectiveness of the programme. It can also be used to assess the changes in the target group; that is, the caregivers of the elderly. The programme can be intended towards assisting the caregiver to become more competent and confident, thereby providing safe and effective care to the elderly, which can indirectly reduce caregiver distress by reducing their load or increasing their sense of certainty and control (Sorensen, Pinquart, Duberstein, 2002). According to Reinhard, Given, Peplic\& Bemis, (2008) caregivers often feel unprepared to provide care owing to the fact that they have inadequate knowledge to deliver proper care, and receive little guidance from the formal health care providers. Some authors predict that, by 2030, the elderly population throughout the world will increase to 973 million, and the number of older adults will be more than triple in developing countries, which will account for $71 \%$ of the world's elderly population. According to You, Deans, Lui, Zhang and Zhang (2004) Statistics in Namibia show that in 2001, there were 122,195 elderly people. The Khomas Region, incorporating Windhoek as the capital, included 8858 elderly people, which represented $7.2 \%$ of all elderly people in Namibia, according to the National Planning Commission (2001).

\section{Purpose of the programme}

The purpose of implementation of programme was to equip caregivers with knowledge and skills on how to care for the elderly.

\section{Discussion of the implementation}

\subsection{Dynamics of the programme}

The dynamics of the programme include the context of an implementation process by means of a workshop, period of implementation and purpose of the programme.

The programme was developed for the use of institutions where the elderly are cared for. The content was offered in five sessions. Who was involved?

The participants involved in the educational programme were the caregivers working in old age homes who must help with the training of other caregivers and registered and enrolled nurses.

\subsection{Implementation of the programme}


Implementation is the carrying out, execution, or practice plan or any design for doing something. Implementation is the action that must follow any preliminary thinking in order for something to happen (Rouse, 2015).

The programme was implemented at the former Potgieter old-age home now called Ouderust Oord, in Windhoek. All participants from five old-age homes: Tabitha, Ouderust Oord, Susanna Grauheim Katutura and Rehoboth, who participated in the situation analysis, were invited to attend. The workshop was held on $18^{\text {th }}$ and $20^{\text {th }}$ December 2009, 30 $0^{\text {th }}$ March 2010, $13^{\text {th }}$ and $20^{\text {th }}$ April 2010 in five sessions on communication, personal hygiene and work proficiency.

Participants from only three old-age homes namely Tabitha, Katutura old-age home and Ouderust Oord attended the workshop. Rehoboth and Susanna Grauheim apologised for not attending, owing to unforeseen circumstances. Altogether, seven participants attended, including one registered nurse, one enrolled nurse and three caregivers, as well as one retired police women and one community caregiver.

The first part of the programme, "Discover the value of interpersonal relationships" was offered to the group of caregivers on 18 December 2009. The second part of the programme, "Develop basic care giving skills" was offered from 20 December 2009, 30 March 2010, 13and 20 April 2010 in five (5) sessions.

\subsection{The workshop}

The researcher and the supervisor at Ouderust Oord old-age home welcomes all the caregivers to the workshop, and opened the workshop with a scripture reading and a prayer.

Participants introduced themselves using an ice breaker by playing the animal game in order to relax the atmosphere and get to know the other participants. They also had to say why they have chosen a certain animal, where they came from and what involvement, they had with the elderly.

Ground rules for the workshop were set: cell phones to be turned off or put on silent mode so as not to disturb the workshop; only one meeting to be held at a time; and speak loud and clear so that everyone can hear.

There after participants were given background information on the workshop, and the objectives were explained.

The workshop was held in the Ouderust Oord old-age home hall, which is beautiful and created a pleasant atmosphere. Cooperation was good, and the nurse manager offered tea and sandwiches to the participants at tea time.

\subsection{Implementation of the programme}

The programme was implemented over a period of five sessions in five days. The researcher makes use of the lectures; brainstorming and demonstration's role plays to teach the participants.

In this programme, demonstrations were of great value to demonstrate procedures to the caregivers so that, in turn; they could practice and demonstrate them to the facilitator in order to make sure they can perform a certain procedure. A demonstration can be defined as a visualized explanation of facts concepts and procedures (Quinn \& Hughes, 2007).

Role play makes it easier to discuss complex social issues in a non-threatening environment and is a powerful training method as it helps to generate awareness (Hasan, 2011). The researcher made use of role play to develop interpersonal and communication skills, as well as conflict resolution and group decision making (Hasan, 2011). Real-life experiences, relevant subject matter or questions were discussed. In the small-group discussions, caregivers were provided with the opportunity to express themselves, which can empower them to realise their ability for critical thinking and, accordingly, change through this medium (Quinn \& Hughes, 2007). Problem solving was also used. Brown and Atkins (1988) (in Quinn \& Hughes, 2007) identify four main stages in problem solving that equate to the following questions:
- What is the nub of the problem?

- Have you met a similar problem before

- What approaches can you use.

- How should you check the solution

Day 1

Guidance towards understanding intra and interpersonal communication

Aim:

- To equip the caregivers with knowledge and skills on understanding the self (intrapersonal skills) as well as effective communication and interpersonal relationships.

THEME: 1

Table 1: Intrapersonal Functioning, Interpersonal Relationships and Communication

Intrapersonal functioning, Interpersonal Relationships and Communication CONTENT ACTIVITIES

Lecture

Group work: Brainstorming, to define communication

Demonstration on model of communication Playing a game to emphasise the importance of communication and to point out obstacles in the process of communication Pictures on various emotions (happy/ sad/
angry and scared) where participants had to recognized

Communication the different intensities of these emotions, with the help of the facilitator.

Game of charades was played to demonstrate the power of non- verbal facial expressions and gestures

Johari's Window was explained to participants and feedback requested to personalise this model.

Self-disclosure

Participants from the same old - aged homes were grouped and requested to write something positive and constructive negative features about another participant. This information is then given to the involved person, who may give feedback on self- disclosure.

Stress and

burnout

Group discussions: Participants were asked to identify triggers which cause stress especially in their work and interpersonal relationships, which were then discussed.

Conflict han- $\quad$ Role play to emphasise effective and inef-

dling fective handling of potentially difficult situations.

The aim of day two, three and four was to provide caregivers with knowledge and skills on basic practical procedures for effective caring, which links with theme

THEME: 2

Table 2: Outline of Implementation of Training of Caregivers in Basic Care

Training of caregivers to fulfil basic needs of the elderly.

Session: 2 and 3

$\begin{array}{cl}\text { CONTENT } & \text { ACTIVITIES } \\ \text { Basic nursing skills } & \\ \text { Bed bath } & \text { Lecture method } \\ \text { Hair wash } & \text { practical demonstrations } \\ \text { Perineal care } & \text { Simulation } \\ \text { Foot and toe nail care } & \text { Feedback by participant } \\ \text { Beard shave } & \\ \text { Session: } 4 & \text { ACTIVITIES } \\ \text { CONTENT } & \text { Lecture Method } \\ \text { Mouth wash } & \text { Demonstrations } \\ \text { Wound care } & \text { Feedback by participants } \\ \text { Medicine care } & \text { Problem solving } \\ \text { Nutrition } & \end{array}$

Session: 5 


\begin{tabular}{|c|c|}
\hline CONTENT & ACTIVITIES \\
\hline $\begin{array}{l}\text { Cardiopulmonary re- } \\
\text { suscitation }\end{array}$ & $\begin{array}{l}\text { Models (dolls) were used } \\
\text { for exercise in simulating cardio- } \\
\text { pulmonary resuscitation to empower } \\
\text { participants to handle emergency } \\
\text { cases. }\end{array}$ \\
\hline $\begin{array}{l}\text { Management of diseas- } \\
\text { es, epilepsy, hypertension, diabe- } \\
\text { tes mellitus, Parkinson, Alzheimer, } \\
\text { Dementia }\end{array}$ & $\begin{array}{l}\text { Participants were taught } \\
\text { how patients with fractures should } \\
\text { be lifted, turned and transferred. } \\
\text { Participants were in- } \\
\text { structed to manage these various } \\
\text { conditions, e.g. for hyper and hypo- } \\
\text { glycemic clients. I.e. testing blood } \\
\text { sugar and to remember to press the } \\
\text { emergency bell to call for help. }\end{array}$ \\
\hline
\end{tabular}

THEME 3:

Table 3: Outline of Implementation of Training of Caregivers in Enhancing Work Proficiency

\begin{tabular}{ll}
$\begin{array}{l}\text { Enhancing work proficiency } \\
\text { CONTENTS }\end{array}$ & \multicolumn{1}{c}{$\begin{array}{c}\text { Lecture method } \\
\text { Opportunity for introspection } \\
\text { Investigation of control systems }\end{array}$} \\
\hline & $\begin{array}{l}\text { implemented in the work place to ensure } \\
\text { punctuality. } \\
\text { Discussion of time management }\end{array}$ \\
& $\begin{array}{l}\text { as linked to self-worth. (I.e. valuing yourself, } \\
\text { will lead to valuing your time). } \\
\text { Discussion of appearance linked }\end{array}$ \\
$\begin{array}{l}\text { Appearance, punctuality, } \\
\text { promptness, leadership, } \\
\text { cooperation, self- } \\
\text { discipline equipment and } \\
\text { material management. }\end{array}$ & $\begin{array}{l}\text { to self-worth. } \\
\text { tion skills. } \\
\text { Discussion linked to communica- } \\
\text { linked to personal integrity, self- worth and } \\
\text { value systems. } \\
\text { Discussion of various leadership }\end{array}$ \\
& $\begin{array}{l}\text { styles. } \\
\text { importance of taking inventory of equipment } \\
\text { and materials as well as reporting broken and } \\
\text { stolen equipment. They were also trained in } \\
\text { using various types of equipment. }\end{array}$ \\
\hline
\end{tabular}

Following is a description of the content disseminated to participants in Session 1 regarding intrapersonal functioning, interpersonal relations and communication.

Knowledge acquisition, skills training and a change in attitude are the three levels involved in acquiring or learning a skill. Below is a schematic representation figure 1 of the three strategies used to effect behaviour change and thus learning in caregivers, within the milieu of managing their work. According to the Reader for Community Health Science (2009), strategies used to aid in be- haviour change of individuals should address change on three levels: the cognitive, or knowledge level, the affective or attitudinal level and the psychomotor or behavioural'/habit/skill level.

The three areas targeted (according to the needs analysis) were improving knowledge, skills and attitudes in intrapersonal functioning, as a starting point, from which more effective interpersonal skills could be developed. In addition, understanding the elderly and basic caring procedures would enable improved quality of care of the elderly.

Methods used to effect behaviour change include modelling, for example, norm, leadership, role play and simulation (affective). Work, skills, activities, projects, or programmes aid in psychomotor/skill development. During presentation of the educational programme, various methods were employed to target all these levels. The self is something which has development; it is not there at birth, but arises in the process of social experience. Becoming a person or unique personality as an ideal social self occurs through communicative interaction with others in the community (Odin, 1996).

The caregiver should be aware of the following

- A person's value system (caregivers, elderly persons, etc.) develops from an early age from parental values (Watson, 2009)

- Values are described as standards of behaviour (Oxford Dictionary, 2005). Therefore personal values influence the way the caregiver or elderly person will act.

Strong values are often attached to religion/spirituality, family relationships, ethnic or cultural groups, roles, educational level, socio-economic status and sexual orientation (Department Occupational Therapy, University of Stellenbosch, 2004)

Social self-suppression leads to the loss of the self

Figure 3 below illustrates how the actions or words of one person towards the thinking, feeling and sensing of another person can lead to suppression of the self in the latter. The expression of feelings, both positive and negative should be accepted, as "feelings alter thoughts and behaviour, and they need to be considered and allowed for in a caring relationship" (Watson, 2009).

Sensitivity to one's self and to others entails the need of the caregiver to begin to feel an emotion as it appears. Development of one's own feelings is needed to interact genuinely and sensitively with elderly persons. Developing sensitivity makes the caregiver more real/genuine and helps to form person-to-person relationships. The caregiver therefore promotes health and higher level functioning. Self-growth and self-actualisation of the caregiver and the elderly person is certain (Watson, 2009). 


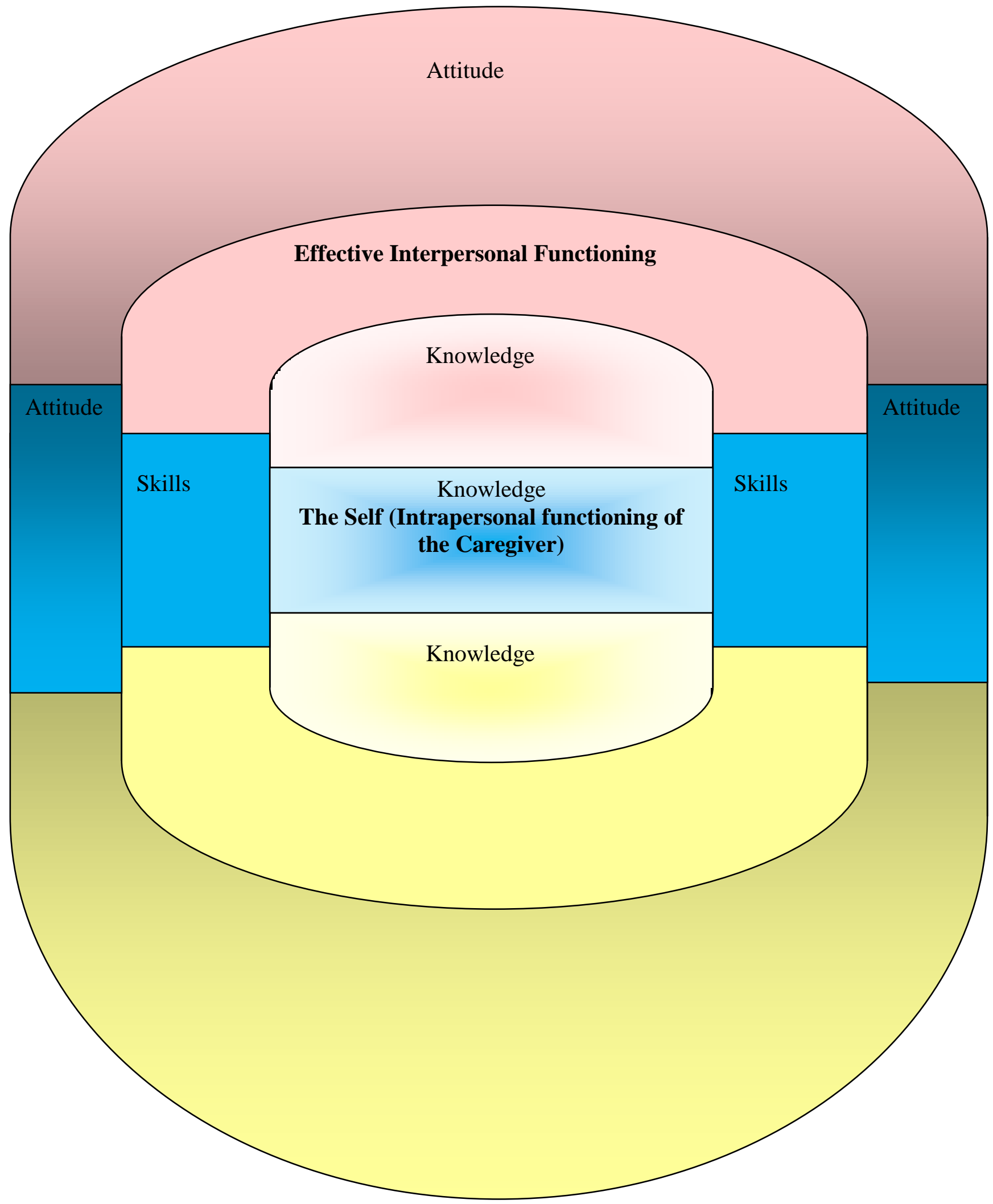

Fig. 1: Schematic Representation of Effective Interpersonal Functioning 
Intrapersonal functioning is essentially characterised by the development of the self. The figure below illustrates this "birth" of the self as a social being.

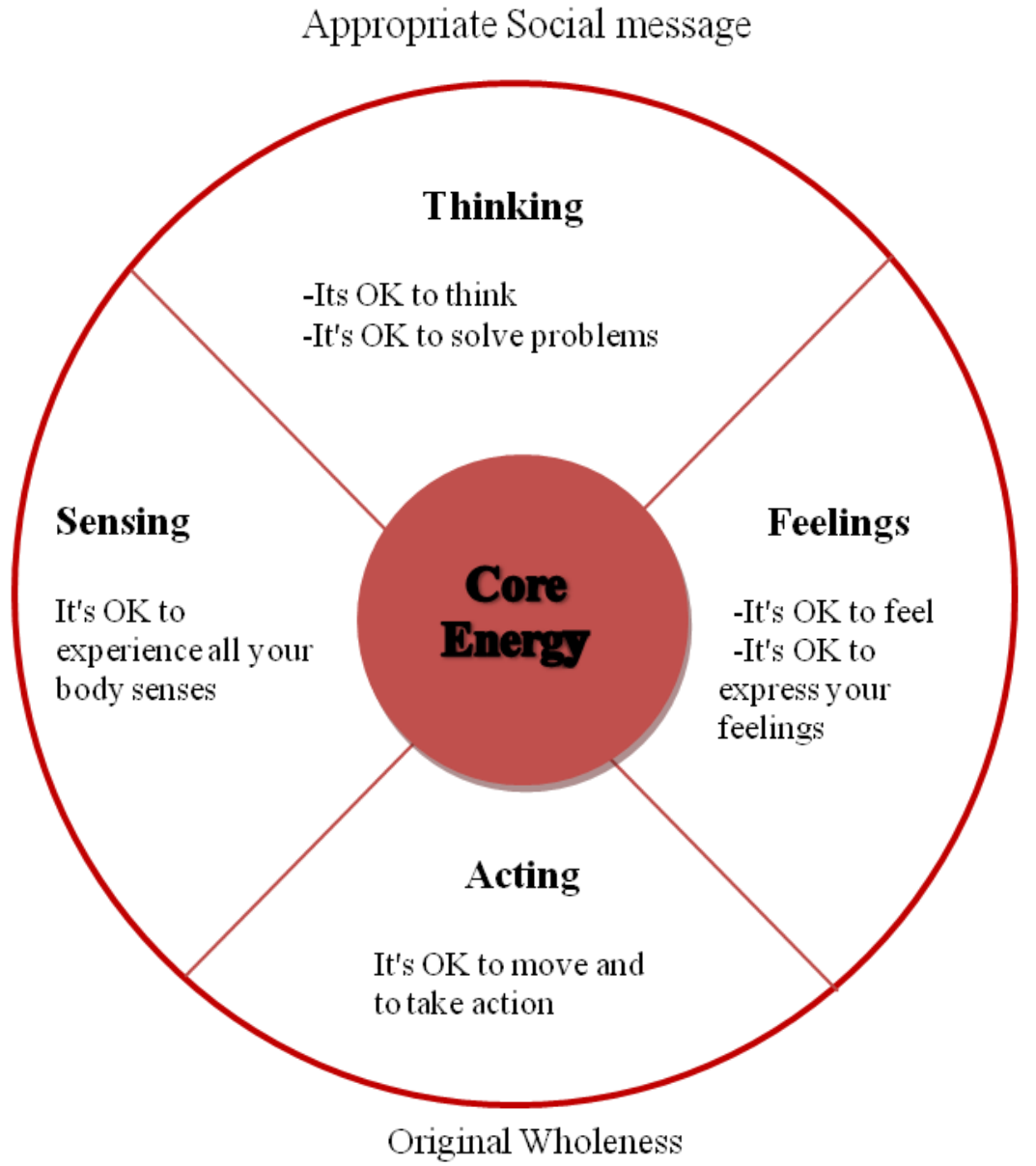

Fig. 2: The Birth of the Social Self (Occupational Notes, 2004).

\section{Thinking}

Don't think certain thoughts

Don't express your thoughts

Don't be smart

Don't act smart
4

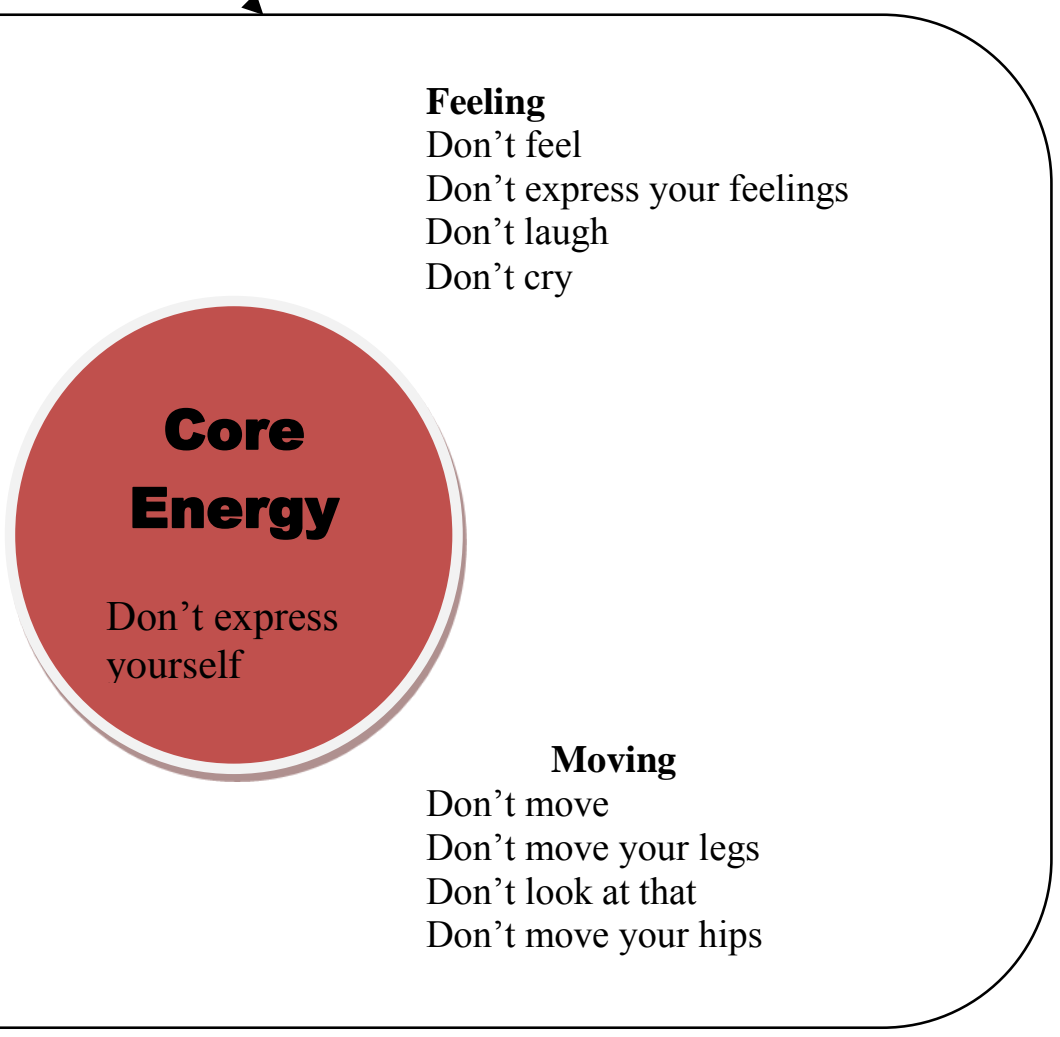


Johari's window below reflects self- disclosure.

Known to self and others $\quad$ Unknown to self

\begin{tabular}{|l|l|}
\hline Free pane & \multicolumn{1}{|c|}{$\begin{array}{c}\text { Blind pane } \\
\text { Feedback }\end{array}$} \\
\hline $\begin{array}{l}\text { Sharing } \\
\text { Hidden pane }\end{array}$ & Revelation \\
& Dark pane \\
\hline
\end{tabular}

Unknown to others

Unknown to self and others

Fig. 4: Johari's Window (Ministry of Health Adolescent Friendly Health Service Notes).Usually there is a General Model of Communication.

The content of the above figure 4 are described as follows:

Free refers to what is known to self and to others. Hidden is the part that is known to but not shared with others. Blind is the part of self which is known to others but unknown to you. Dark the part of you that is unknown to you and the others. The feedback is the way the others can open the blind area in yourself by letting you know what they see in you what you do not see in yourself Sharing the way of opening yourself to others.

Each day as people communicate with others. They use different modes of speaking, listening, writing, reading and nonverbal communication. There are four basic elements in all communications.

A person who originates a thought or idea.

The idea itself, as it is expressed.

A medium or channel for expressing the idea

Someone to receive and interpret the idea.

The communication process can be summarised by examining the following model: Communication takes place when two or more people exchange messages using verbal and nonverbal language; communication happens because people want to share information, ideas feeling and thoughts. Figure 5 shows a model of communication.

Communication is an integral part of interpersonal functioning.

The communication process can be explained by examining the following model:

\section{Feedback}

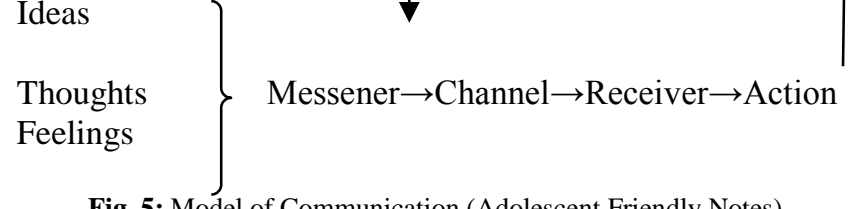

Fig. 5: Model of Communication (Adolescent Friendly Notes)

- Sender: The sender wants to transmit the intended content of the message. Accordingly, the sender has ideas, intentions and information.

- Encoding the message: The ideas are organised in a suitable context for the transmission medium so that they can be expressed as a message.

- Channel of the message: as encoded by the selected medium.

- Receiving the intended message: The receiver enters the process to receive the message

- Decoding: The receiver decodes the message in terms of relevance to him/her.

- Action of the receiver: In this step the receiver acts or responds by filing the information.

- Feedback to the sender: Communication has taken place only when there is some form of acknowledgement given to the sender that the message has been received (Baird, 1984).

Activity 1
Role plays can be conducted by caregivers concerning good and bad communication

Important aspects relating to intra- and interpersonal relations have been highlighted above.

\section{Conclusion}

The educational programme was implemented in five sessions over five days at the Ouderust Oord old-age home. In long- term care settings, caregivers are those people who spend most of the time with the elderly, and they can be the important source of psychosocial information and support Miller (1999) (in Capezuti, Siegler, \& Mezey, 2008).Subsequently, Subsequently, an educational programme was developed from the themes and categories identified by the research. The educational programme consists of three sessions comprising the following learning content:

Session 1: Discover the value of good interpersonal relationships

Session 2: Improve knowledge and skills of practical procedures in order to improve physical care and proper nutrition

Session 3: Guidance given on specific managerial aspects

The implementation of the educational programme was a success, based on the comments that the participants made during the focus group discussion.

Acknowledgement

This article was extracted from the authors study "Caregiving in old-age homes in Windhoek. A practice-orientated enquiry into care giving education." I would like to thank the caregivers of the elderly for their participation in the implementation of the programme. The Management of the different old-age homes for releasing the caregivers to attend the workshops. Ethical aspects were adhered to.

\section{References}

[1] Arthur, D., Pang, S., \& Wong, T. (2011) Evidence for caring behaviour: $\mathrm{www} / / \mathrm{knowledge.scot.nhs.uk/...} \mathrm{caring,} \% 20$ behaviours.

[2] Baird, C. G. (1984). The power of positive self- image. Wheaton: Victor Books

[3] Capezuti, L., Siegler, E. L., \&Mezey, M.D. (2008) Encyclopedia of Elder care: New York: Springer

[4] Clarke, M. J. (2008) Community health nursing: Advocacy for population health (5th Ed.). New Jersey, Prentice-Hall.

[5] Department of Ocupational Therapy (2004) Occupational Therapy 3. Stellenbosch: University of Stellenbosch.

[6] Dolon, D., \& Holt, L. (2000)Accident and emergency theory in to practice; http://wwwgoogle.com,nal\#htl=en\&source=hp\&stoyle+1

[7] Gorman, M. (2006) Development and the rights of older people. In J. Randel et al. (Eds), ageing and development report: Poverty, independence and the world's older people. London: Earth scan.

[8] Hasan, (2011) Improving E- Learning system using automated Document. http://idosi.org/wasj/wasj.12(CA\&KM)/3pdf.

[9] Hornby, A.S. (2006) Advanced Oxford Dictionary. $7^{\text {th }}$ (Ed.). Oxford University Press Inc New York

[10] Implementation/defineImplementation@ dictionary.Comdictionary.reference.com/ browse/implementationhttp://wwwcom/search=Implementation 
[11]Khosravani, S., Manoochehri, H., Memarian, R., (2005) Developing critical thinking skills in nursing students by group; The internet Journal of advanced Nursing Practice, volume 7 number 2.

[12]Ministry of Health and Social Services. (2004) Adolescent friendly health services notes.

[13] National Planning Commission. (2001) OPCIT midterm report Review NDP.Report

[14]Odin, S. (1996).The social self in Zen and American Pragmatism. New York: State University of New York Press

[15]Pusari, N. D. (1998) Eight C's of caring: A holistic framework for nursing terminally ill patients'doi: 10 5172/conu1998.7.3.156.http:www.contempory nurse.com

[16]Quinn, F. M., \& Hughes, (2007) Quinn's principles and practice of nurse education (5th Ed.). Cheltenham: Nelson Thornes.

[17]Reinhardt, B., Given, B., Peplic, H., \& Bemis, A. (2008) Suporting family caregivers in providing care. Rockville Agency for Health Care; Research and quality http://www.ncbi.nlmnih.gov/books/NBK2665.

[18]Rouse, M. (2015). Implementation Search CRM http://searchcrm.techtarget.com/definition.

[19] Smith, K. V., \& Godfrey, N.S. (2002) Being a good nurse and doing the right thing: a qualitative study. Nursing ethics 2002, a (3), 301312. http://dx.doi.org/10.1191/0969733002ne512oa.

[20]Sorensen, S., Pinquart, M., \& Dubersten, P. (2002) How effective are interventions with caregivers? An updated meta-analysis. Gerontologist.42, 356-72 [Pubmed]. http://dx.doi.org/10.1093/geront/42.3.356.

[21] Reader for Community Health Science, (2009) University of Namibia.

[22]You, L., Deans, C., Liu, K., Zhang, M. F., \& Zhang, J. (2004). Rising awareness of fall risk among Chinese older adults: Use of the home fall hazards assessment tool. Journal of Gerontological Nursing, 30(6). http://dx.doi.org/10.3928/0098-9134-20040601-08.

[23] Watson, J. (2009). Theory of Nursing. http://currentnursing.com /nursing theory/Watson/html. 